\title{
A Mononuclear Fe(III) Single Molecule Magnet with a 3/25/2 Spin Crossover
}

Mossin, Susanne L.; Tran, Ba L.; Adhikari, Debashis; Pink, Maren; Heinemann, Frank W.; Sutter, Jorg; Szilagyi, Robert K.; Meyer, Karsten; Mindiola, Daniel J.

Published in:

Journal of the American Chemical Society

Link to article, DOI:

10.1021/ja302660k

Publication date:

2012

Document Version

Publisher's PDF, also known as Version of record

Link back to DTU Orbit

Citation $(A P A)$ :

Mossin, S. L., Tran, B. L., Adhikari, D., Pink, M., Heinemann, F. W., Sutter, J., Szilagyi, R. K., Meyer, K., \& Mindiola, D. J. (2012). A Mononuclear Fe(III) Single Molecule Magnet with a 3/25/2 Spin Crossover. Journal of the American Chemical Society, 134(33), 13651-13661. https://doi.org/10.1021/ja302660k

\section{General rights}

Copyright and moral rights for the publications made accessible in the public portal are retained by the authors and/or other copyright owners and it is a condition of accessing publications that users recognise and abide by the legal requirements associated with these rights.

- Users may download and print one copy of any publication from the public portal for the purpose of private study or research.

- You may not further distribute the material or use it for any profit-making activity or commercial gain

- You may freely distribute the URL identifying the publication in the public portal 


\section{A Mononuclear Fe(III) Single Molecule Magnet with a $3 / 2 \leftrightarrow 5 / 2$ Spin Crossover}

Susanne Mossin, ${ }^{*}{ }^{\dagger}$ Ba L. Tran, ${ }^{\ddagger}$ Debashis Adhikari, ${ }^{\ddagger}$ Maren Pink, ${ }^{\ddagger}$ Frank W. Heinemann, ${ }^{\S}$ Jörg Sutter, ${ }^{\S}$ Robert K. Szilagyi, ${ }^{\text {II }}$ Karsten Meyer, ${ }^{*}$, and Daniel J. Mindiola*, ${ }^{*}$

${ }^{\dagger}$ Center for Catalysis and Sustainable Chemistry, Department of Chemistry, Technical University of Denmark, 2800 Lyngby, Denmark

${ }^{\ddagger}$ Department of Chemistry and the Molecular Structure Center, Indiana University, Bloomington, Indiana 47405, United States

${ }^{\S}$ Inorganic Chemistry, Friedrich-Alexander University Erlangen-Nuremberg, Erlangen, Germany 91058

${ }^{\mathrm{I}}$ Department of Chemistry and Biochemistry, Montana State University, Bozeman, Montana 59717, United States

\section{Supporting Information}

ABSTRACT: The air stable complex $\left[(\mathrm{PNP}) \mathrm{FeCl}_{2}\right](1)(\mathrm{PNP}=\mathrm{N}[2-$ $\mathrm{P}\left(\mathrm{CHMe}_{2}\right)_{2}-4$-methylphenyl $\left.]_{2}^{-}\right)$, prepared from one-electron oxidation of $[(\mathrm{PNP}) \mathrm{FeCl}]$ with $\mathrm{ClCPh}_{3}$, displays an unexpected $S=3 / 2$ to $S=5 / 2$ transition above $80 \mathrm{~K}$ as inferred by the dc SQUID magnetic susceptibility measurement. The ac SQUID magnetization data, at zero field and between frequencies 10 and $1042 \mathrm{~Hz}$, clearly reveal complex 1 to have frequency dependence on the out-of-phase signal and thus being a single molecular magnet with a thermally activated barrier of $U_{\text {eff }}=32-$ $36 \mathrm{~cm}^{-1}(47-52 \mathrm{~K})$. Variable-temperature Mössbauer data also
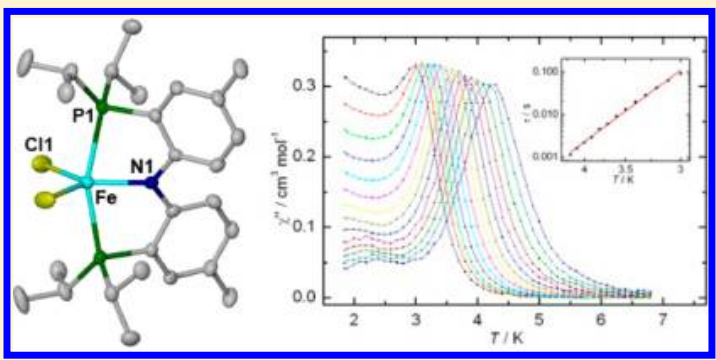
corroborate a significant temperature dependence in $\delta$ and $\Delta E_{\mathrm{Q}}$ values for 1 , which is in agreement with the system undergoing a change in spin state. Likewise, variable-temperature X-band EPR spectra of 1 reveals the $S=3 / 2$ to be likely the ground state with the $S=5 / 2$ being close in energy. Multiedge XAS absorption spectra suggest the electronic structure of 1 to be highly covalent with an effective iron oxidation state that is more reduced than the typical ferric complexes due to the significant interaction of the phosphine groups in PNP and Cl ligands with iron. A variable-temperature single crystal X-ray diffraction study of 1 collected between 30 and $300 \mathrm{~K}$ also reveals elongation of the Fe$\mathrm{P}$ bond lengths and increment in the $\mathrm{Cl}-\mathrm{Fe}-\mathrm{Cl}$ angle as the $S=5 / 2$ state is populated. Theoretical studies show overall similar orbital pictures except for the $\mathrm{d}\left(z^{2}\right)$ orbital, which has the most sensitivity to change in the geometry and bonding, where the quartet $\left({ }^{4} \mathrm{~B}\right)$ and the sextet $\left({ }^{6} \mathrm{~A}\right)$ states are close in energy.

\section{INTRODUCTION}

Many applications have been envisioned for single molecules with an energy barrier to magnetic relaxation; among these are information storage, quantum computing, spintronics, and magnetic refrigeration. ${ }^{1}$ These properties have been sought in clusters having strongly coupled transition-metal ions ever since the discovery of the magnetic properties of the parent $\mathrm{Mn}_{12}$ cluster, one of the most intensely studied single molecule magnets (SMM) to date. ${ }^{2-4}$ The properties of SMM are usually related to high magnetic anisotropy and high spin quantum numbers; however, in spite of a tremendous effort, it has so far not been possible to develop or predict a system with a sufficient high blocking temperature, often because tunneling of the magnetization occurs at lower temperatures. Nevertheless, investigations into the many new nanoscale magnets have provided insights into the physics on the limit between single centers and extended structures. An important contribution toward designing new magnetic materials would be to understand the effects governing the behavior at the single center level and to limit the detrimental effects of tunneling on the total magnetization. Several single center lanthanide and actinide compounds have been shown to behave like SMM, ${ }^{5}$ but recent studies by Chang and Long et al. proved that a $3 \mathrm{~d}$ transition-metal system, such as iron(II), can also display slow magnetic relaxation. These complexes, which are $\left[\left(\mathrm{tpa}^{\mathrm{R}}\right) \mathrm{Fe}\right]^{-}$ where $\mathrm{H}_{3} \mathrm{tpa}^{\mathrm{R}}$ is a family of tris(pyrrolyl- $\alpha$-methyl)amine ligands, with $\mathrm{R}$ being different alkyl or aryl substituents on the pyrrole ring, are the first examples of a mononuclear transition-metal complex, which have single molecule magnetlike behavior (Figure 1a). ${ }^{6}$ The latter series of high spin trigonal $\mathrm{Fe}(\mathrm{II})$ complexes show varying degrees of slow relaxation upon

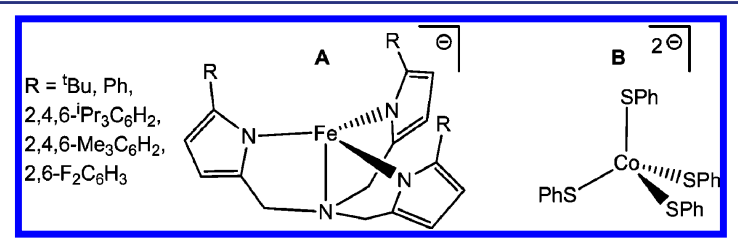

Figure 1. Mononuclear 3d transition-metal SMM.

Received: March 19, 2012

Published: July 22, 2012 
application of an external dc field. Despite having a very high local anisotropy, the response is severely limited since extended tunneling takes place in zero applied field. Interestingly, when $\mathrm{R}$ $=$ tbutyl and phenyl, the onset of slow relaxation in zero magnetic field is observable on the faster Mössbauer time scale. Other examples of iron(II) systems that show slow relaxation of the magnetization in an applied $\mathrm{dc}$ magnetic field are $\left[\mathrm{Fe}\left(\mathrm{N}\left(\mathrm{SiMe}_{3}\right)_{2}\right)_{2}\left(\mathrm{PCy}_{3}\right)\right]$ and $\left[\mathrm{Fe}\left(\mathrm{N}\left(\mathrm{SiMe}_{3}\right)_{2}\right)_{2}\right.$ (deppe $\left.)\right]$ and $\left[\mathrm{CpFe}\left(\mathrm{C}_{6} \mathrm{H}_{3}{ }^{i} \mathrm{Pr}_{3}-2,6\right)\right]$ (Cy = cyclohexyl, deppe =1,2-bis(diethylphosphino)ethane, $\mathrm{Cp}=$ cyclopentadienyl). ${ }^{7}$ Recently, it was also discovered that a tetrahedral $\mathrm{Co}$ (II) complex (Figure 1b) can be also a SMM, and this system shows slow magnetic relaxation in zero applied field. ${ }^{8 a}$ Another Co(II) system containing a pincer ligand was shown to have SMM behavior but under an applied dc field. ${ }^{8 b}$ We present the first single center iron complex to exhibit slow relaxation of the magnetization in zero applied field on a time scale, where it can be probed by ac susceptibility as well as Mössbauer spectroscopy: the iron(III) complex [(PNP) $\left.\mathrm{FeCl}_{2}\right]$ (1, with $\left.\mathrm{PNP}=N\left[2-\mathrm{P}\left(\mathrm{CHMe}_{2}\right)_{2}-4 \text {-methylphenyl }\right]_{2}^{-}\right)$. Complex 1 has been studied in the solid state by variable-temperature (VT) zero field Mössbauer spectroscopy, VT X-band EPR spectroscopy, ac/dc variable-temperature variable-frequency (VT-VF) SQUID magnetization, multiedge X-ray absorption spectroscopy, and VT single crystal X-ray diffraction analysis. In addition, DFT calculations were carried out to collate the experimental data and develop an understanding of the electronic structure for this unique system. The small size, the neutral charge, and the half-integer spin ground state of the molecule make this system ideal for studies of its properties as a singular center molecular magnet. In addition to the SMM ferric complex 1, we compare and contrast the experimental and theoretical results to a structurally and compositionally similar, yet largely electronically and magnetically different, reference iron(III) complex.

The current strategy in the SMM literature has been to synthesize systems having a high axial symmetry (trigonal or tetragonal) in addition to a high spin quantum number. Contrary to this paradigm, we demonstrate here that complex 1 is a legitimate single molecular magnet at low temperatures despite having low symmetry (a two-fold axis) and an intermediate spin quantum number of $S=3 / 2$. The unique nature of the pentacoordinated $\mathrm{Fe}$ (III) complex $\mathbf{1}$ is also evidenced by a predominantly intermediate spin state (IS, $S=$ $3 / 2$ ) at low temperatures with a high spin state (HS, $S=5 / 2$ ) being gradually populated at temperatures above $80 \mathrm{~K}$. This spin transition is highly unusual for non-porphyrin iron(III), and a range of spectroscopies will be presented in order to probe the transition. To address the oxidation state of the iron center and whether change occurs during the course of the transition, we present a combination of Mössbauer and multiedge XAS data.

\section{RESULTS}

Synthesis of Complexes 1 and 2. Analytically pure, darkviolet crystals of air-stable 1 can be readily prepared in over $80 \%$ yield from the one-electron oxidation of $[(\mathrm{PNP}) \mathrm{FeCl}]^{9}$ with $\mathrm{Ph}_{3} \mathrm{CCl}$ in THF (Scheme 1). The precursor to $\mathbf{1}$ can be readily prepared in multigram scales using $\left[\mathrm{FeCl}_{2}(\mathrm{THF})\right]^{10}$ and $[\mathrm{Li}(\mathrm{PNP})]$ in $\mathrm{Et}_{2} \mathrm{O} .^{9}$ Gomberg's dimer, ${ }^{11}$ which was detected as a quinonoid-like structure by ${ }^{1} \mathrm{H}$ NMR spectroscopy, can be washed away with THF and copious amounts of $\mathrm{Et}_{2} \mathrm{O}$ followed by pentane. ${ }^{12}$ An MS-CI spectrum of 1 revealed the expected
Scheme 1. Synthesis of Complexes 1 and 2 from Oxidation of $[(\mathrm{PNP}) \mathrm{FeCl}]$

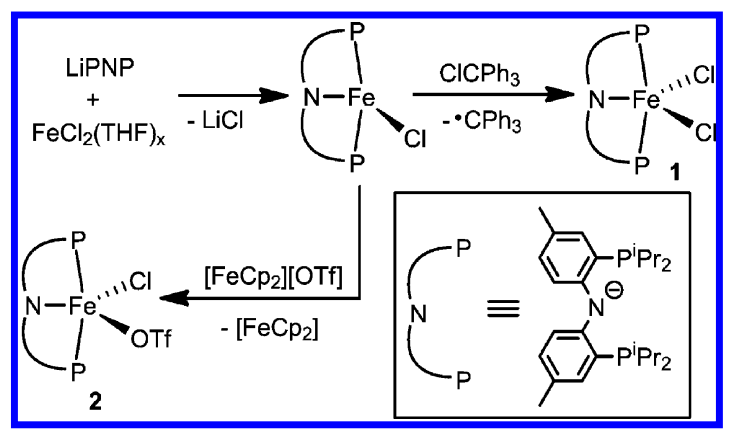

ion $[\mathrm{M}-\mathrm{Cl}]^{+}$at 519.168 (calcd is 519.867$)$. A close relative to 1, complex [(PNP) $\mathrm{FeCl}(\mathrm{OTf})](2)$, can be similarly prepared by oxidation of $[(\mathrm{PNP}) \mathrm{FeCl}]$ with $\left[\mathrm{FeCp}_{2}\right][\mathrm{OTf}]^{13}$ in THF (Scheme 1). ${ }^{12,14}$ The purple solid, which is soluble in $\mathrm{CH}_{2} \mathrm{Cl}_{2}$ and sparingly soluble in THF and most common organic solvents, is obtained in $87 \%$ isolated yield after repeatedly being washed with $\mathrm{THF}, \mathrm{Et}_{2} \mathrm{O}$, and pentane to remove $\mathrm{FeCp}_{2}$ and traces of unreacted $[(\mathrm{PNP}) \mathrm{FeCl}] .^{12,14}$ Unlike 1, which can be crystallized readily from a $\mathrm{CH}_{2} \mathrm{Cl}_{2}$ solution layered with $\mathrm{Et}_{2} \mathrm{O}$, repeated attempts to crystallize complex 2 only resulted in powders although with the correct formula $\mathrm{C}_{26} \mathrm{H}_{40} \mathrm{NP}_{2} \mathrm{O}_{3} \mathrm{SF}_{3} \mathrm{ClFe}$ based on $\mathrm{C}, \mathrm{H}$, and $\mathrm{N}$ combustion analysis. Complexes $\mathbf{1}$ and $\mathbf{2}$ show broadened and paramagnetically shifted resonances ranging from 109 to $-113 \mathrm{ppm}$ in their ${ }^{1} \mathrm{H}$ NMR spectra. Although these species have similar melting points $\left(184{ }^{\circ} \mathrm{C}\right.$ for $1,169{ }^{\circ} \mathrm{C}$ for 2$)$ and similar colors, the electronic absorption spectrum of 1 reveals three red-shifted bands at $902 \mathrm{~nm}\left(\varepsilon=2908 \mathrm{M}^{-1} \mathrm{~cm}^{-1}\right), 536(\varepsilon=4105$ $\left.\mathrm{M}^{-1} \mathrm{~cm}^{-1}\right)$, and $386 \mathrm{~nm}\left(\varepsilon=4094 \mathrm{M}^{-1} \mathrm{~cm}^{-1}\right)$ when compared to the three bands observed for 2 at $854 \mathrm{~nm}(\varepsilon=456$ $\left.\mathrm{M}^{-1} \mathrm{~cm}^{-1}\right), 536\left(\varepsilon=418 \mathrm{M}^{-1} \mathrm{~cm}^{-1}\right)$, and $386 \mathrm{~nm}(\varepsilon=7156$ $\left.\mathrm{M}^{-1} \mathrm{~cm}^{-1}\right)$. Based on these spectroscopic features we propose that $\mathbf{1}$ and $\mathbf{2}$ should have similar geometries and that the OTf is most likely coordinated to the metal center given the fact that we observe a very broad $\left(\Delta \nu_{1 / 2}=1853 \mathrm{~Hz}\right)$ and paramagnetically shifted resonance at $10 \mathrm{ppm}$ in the ${ }^{19} \mathrm{~F}$ NMR spectrum. We have also found that attempts to prepare a discrete salt, such as $[(\mathrm{PNP}) \mathrm{FeCl}]\left[\mathrm{PF}_{6}\right]$ in $\mathrm{CH}_{2} \mathrm{Cl}_{2}$, resulted in immediate formation of 1 along with other unidentified side products. As a result, we propose the $\mathrm{OTf}^{-}$ligand to be coordinated in complex 2, given its inertness toward halogenated solvents, such as $\mathrm{CH}_{2} \mathrm{Cl}_{2}$ and $\mathrm{CHCl}_{3}$.

Structural Characterization of Complex 1. A single crystal X-ray diffraction study of 1 at $150 \mathrm{~K}$ clearly shows a mononuclear, five-coordinate iron center in the pincer-like grip enforced by the tridentate $\mathrm{PNP}^{-}$ligand (Figure 2, top). ${ }^{12}$ Complex 1 crystallizes in the centrosymmetric space group P2/ $n$ having symmetry transformations: $(x, y, z),(-x+1 / 2, y,-z$ $+1 / 2),(-x,-y,-z)$, and $(x-1 / 2,-y, z-1 / 2)$. In the molecular structure of $\mathbf{1}$, the complex is formally between trigonal bipyramidal (tbp with $\mathrm{P}-\mathrm{Fe}-\mathrm{P}$ as the main axis) and square pyramidal with a chloride at the apex. The distortion index, $\tau$, ${ }^{15}$ of 0.55 is only slightly closer to tbp, where the two axial phosphine ligands are much stronger donors than the three equatorial ligands, namely, the amide nitrogen and the two chlorides. Therefore, for the purpose of clarity, we will describe the system as a distorted tbp with the strong donors along the main axis defined by $\mathrm{P}-\mathrm{Fe}-\mathrm{P}$. A two-fold axis is 


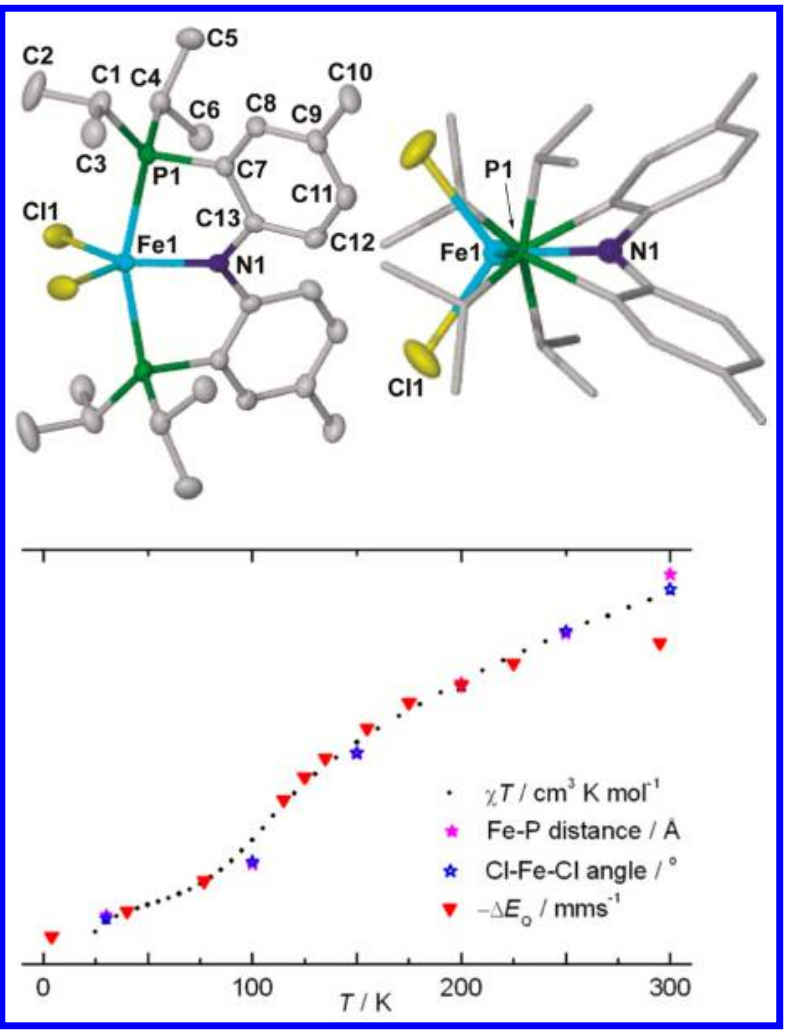

Figure 2. (top) Molecular structure of complex 1 and a view down the $\mathrm{P}-\mathrm{Fe}-\mathrm{P}$ axis at $150(2) \mathrm{K}$ depicting thermal ellipsoids at the $50 \%$ probability level. Selected bond lengths $(\AA)$ and angles $\left({ }^{\circ}\right)$ : Fe1-Cl1, 2.2694(6); Fe1-P1, 2.3761(5); Fe1-N1, 1.972(2); shortest interatomic $\mathrm{Fe} \cdots \mathrm{Fe}$ distance $~ 9.51 ; \mathrm{Cl} 1-\mathrm{Fe} 1-\mathrm{N} 1,125.935(19) ; \mathrm{P}^{\prime}{ }^{\prime}-$ $\mathrm{Fe} 1-\mathrm{P} 1,158.81(3) ; \mathrm{Cl1}-\mathrm{Fe} 1-\mathrm{P} 1,92.974(17) ;$ angle between aromatic planes, 51.52. (bottom) A graph depicting structural changes in the $\mathrm{Fe}-\mathrm{P}$ distances and $\mathrm{Cl}-\mathrm{Fe}-\mathrm{Cl}$ angles (error values on structural parameters are within the symbols shown) as well as the $\chi \mathrm{T}$ from dc susceptibility and (minus) the quadrupole moment from Mössbauer spectroscopy. All values are obtained in the temperature range $4-300 \mathrm{~K}$ and have been plotted in the same graph with rescaled $y$-axes in order to qualitatively compare the gradual temperature dependence of the different physical parameters.

present in 1 , containing the $\mathrm{Fe}-\mathrm{N}$ bond and bisecting the two chloride ligands. The aromatic rings are twisted to avoid collision of the hydrogens on carbons adjacent to the amide carbon atom, rendering the pincer ligand $C_{2}$ symmetric. The iron centers are well separated with the closest interatomic distance being $\sim 9.5 \AA$. This distance compares well with the intermolecular Co $\cdots$ Co distance $(\sim 11.7 \AA)$ reported for the SMM complex $\left[\mathrm{Ph}_{4} \mathrm{P}\right]_{2}\left[\mathrm{Co}(\mathrm{SPh})_{4}\right]^{16}$

Due to the fact that complex 1 displays temperaturedependence magnetic properties, we conducted VT single crystal X-ray diffraction studies to understand the structural changes associated with these magnetic properties. In addition to the solid-state structure collected at $150 \mathrm{~K}$, five other structural data sets of high resolution were collected on the same single crystal at $30,100,200,250$, and $300 \mathrm{~K}^{12}$ Selected structural features for the first coordination sphere of the molecular structures of compound $\mathbf{1}$ are listed in Table 1 . As the temperature increases, an increase in the $\mathrm{Fe}-\mathrm{P}$ distance $(\sim 0.1 \AA)$, a slight increase of the $\mathrm{Fe}-\mathrm{N}$ distance $(\sim 0.02 \AA)$, and a slight decrease of the $\mathrm{Fe}-\mathrm{Cl}$ distance $(\sim 0.02 \AA)$ are observed. Other relevant structural changes are the significant increment in the $\mathrm{Cl}-\mathrm{Fe}-\mathrm{Cl}$ angle at high temperatures $\left(\sim 6^{\circ}\right)$ and a more modest decrease of the $\mathrm{P}-\mathrm{Fe}-\mathrm{P}$ angle $\left(\sim 2^{\circ}\right)$. Clearly the gradual development in structural parameters is nonlinear around $100 \mathrm{~K}$ (Figure 2), and the same trend is also observed in both dc susceptibility, EPR, and Mössbauer spectroscopy (vide infra).

Magnetic Measurements of Complexes 1 and 2 . Solution magnetic susceptibility measurement of 1 at $298 \mathrm{~K}$ (room temperature $=\mathrm{RT}$ ) by the method of Evans shows a higher $\chi T$ of $2.3(2) \mathrm{cm}^{3} \mathrm{~K} \mathrm{~mol}^{-1}\left(\mathrm{CDCl}_{3}\right)$ when compared to complex $2\left(1.4(4) \mathrm{cm}^{3} \mathrm{~K} \mathrm{~mol}^{-1}, \mathrm{CDCl}_{3}\right)$. Unfortunately, the poor solubility of $\mathbf{2}$ could render the magnetic data in solution rather unreliable. To obtain more precise information about the magnetic properties of $\mathbf{1}$ and $\mathbf{2}$, we collected SQUID magnetization data of microcrystalline samples. The dc SQUID data for complex 2 show a slightly temperaturedependent value of $\chi T$ of 2.2 to $2.4 \mathrm{~cm}^{3} \mathrm{~K} \mathrm{~mol}^{-1}$ over the temperature range $25-300 \mathrm{~K}$ (dc mode, top of Figure 3 ). The plot of $\chi T$ as a function of temperature for complex $\mathbf{2}$ is consistent with an IS spin $\mathrm{Fe}$ (III) center $(S=3 / 2)$. In contrast, complex 1 displays a significantly more temperature-dependent magnetic moment over the entire range from 2 to $300 \mathrm{~K}$. To further investigate the magnetic properties of complex $\mathbf{1}$ and 2, SQUID data were collected in dc mode in the temperature range $2-300 \mathrm{~K}$ at a field of 1,3 , and $5 \mathrm{~T}(\mathrm{~T}$ ) (bottom of Figure $3)$; data reproducibility was confirmed on several independently synthesized samples. ${ }^{12}$ The results show a behavior typical of IS iron(III) with pronounced zero field splitting (zfs) at temperatures below $80 \mathrm{~K}$. The data were fitted to an $S=3 / 2$ spin Hamiltonian:

$$
H=D\left(S_{z}^{2}-S(S+1)\right)+E\left(S_{x}^{2}-S_{y}^{2}\right)+\mu_{\mathrm{B}} g S \cdot B
$$

Table 1. Experimental Bond Distances $(\AA ̊)$ and Angles (deg) for 1 Obtained from X-ray Crystallography at Different Temperatures $^{a}$

\begin{tabular}{|c|c|c|c|c|c|c|c|c|}
\hline & $30 \mathrm{~K}$ & $100 \mathrm{~K}$ & $150 \mathrm{~K}$ & $200 \mathrm{~K}$ & $250 \mathrm{~K}$ & $300 \mathrm{~K}$ & calcd IS & calcd HS \\
\hline $\mathrm{Fe} 1-\mathrm{P} 1$ & $2.3277(5)$ & $2.3430(4)$ & $2.3761(5)$ & $2.3971(5)$ & $2.4120(5)$ & $2.4297(8)$ & 2.337 & 2.566 \\
\hline $\mathrm{Fe} 1-\mathrm{Cl} 1$ & $2.2847(5)$ & $2.2775(5)$ & $2.2694(6)$ & $2.2643(6)$ & $2.2607(6)$ & $2.2570(8)$ & 2.316 & 2.294 \\
\hline $\mathrm{Fe} 1-\mathrm{N} 1$ & $1.964(2)$ & $1.965(2)$ & $1.972(2)$ & $1.975(2)$ & $1.981(2)$ & $1.981(2)$ & 1.949 & 2.013 \\
\hline $\mathrm{Cl1}^{\prime}-\mathrm{Fe} 1-\mathrm{Cl} 1$ & 104.84(3) & $105.86(3)$ & $107.83(4)$ & $109.04(4)$ & $110.03(5)$ & $110.79(6)$ & 100.0 & 114.0 \\
\hline $\mathrm{P} 1^{\prime}-\mathrm{Fe} 1-\mathrm{P} 1$ & $159.73(3)$ & $159.38(3)$ & $158.81(3)$ & $158.43(3)$ & $158.13(3)$ & $157.96(3)$ & 162.7 & 155.4 \\
\hline $\mathrm{P} 1-\mathrm{Fe} 1-\mathrm{N} 1$ & $79.864(16)$ & $79.692(14)$ & $79.406(15)$ & $79.216(15)$ & $79.066(15)$ & $78.978(16)$ & 81.3 & 78.4 \\
\hline$\angle \mathrm{Ar}$ & 50.08 & 50.76 & 51.52 & 52.24 & 52.70 & 53.27 & 49.8 & 56.6 \\
\hline
\end{tabular}

${ }^{a} \angle \mathrm{Ar}$ gives the angle between the aromatic planes. The two columns to the right contain calculated values for the intermediate-spin (IS) and the high spin (HS) states computed at the B3LYP/TZVP level of theory. 


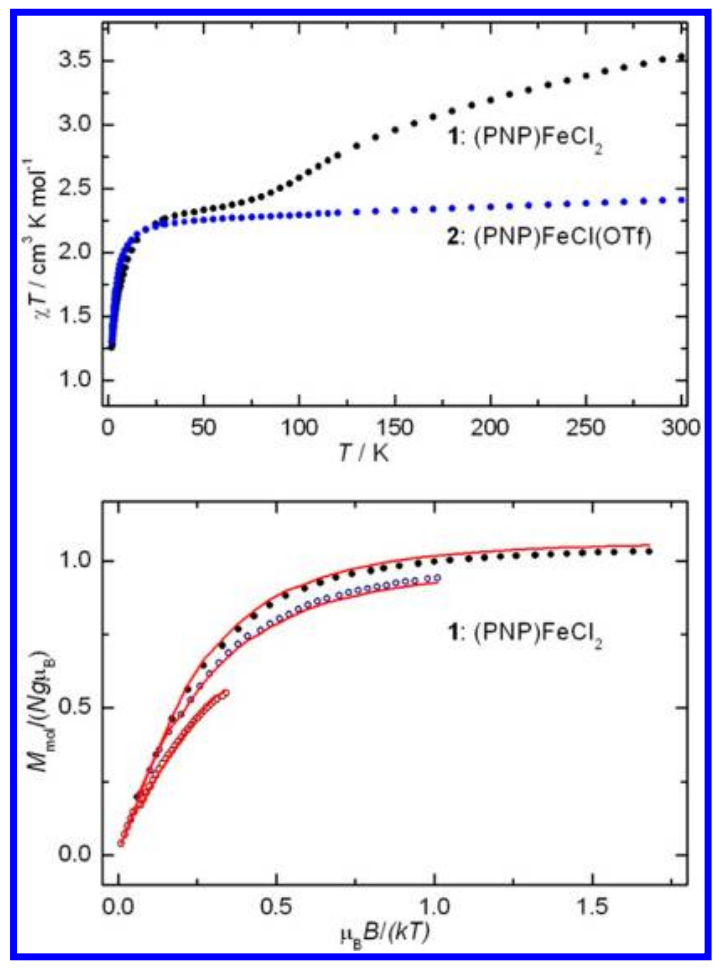

Figure 3. (top) dc magnetic susceptibility of $\mathbf{1}$ (black) and 2 (blue) measured at $1 \mathrm{~T}$ in the temperature range $2-300 \mathrm{~K}$. (bottom) dc magnetic susceptibility of 1 measured in the temperature range 2-50 $\mathrm{K}$ at 1,3 , and $5 \mathrm{~T}$ and simulation (red) using an $S=3 / 2$ spin Hamiltonian with the parameters $g_{\text {iso }}=2.2, D=-11 \mathrm{~cm}^{-1}$.

In the $2-50 \mathrm{~K}$ temperature interval, this provides $g=2.2(1), D$ $=11(3) \mathrm{cm}^{-1}$, and $E / D<0.01 \mathrm{~cm}^{-1}$ for 1 and $g=2.2(1), D=$ $-6(2) \mathrm{cm}^{-1}$, and $E / D<0.01 \mathrm{~cm}^{-1}$ for 2, respectively. ${ }^{12} \mathrm{At}$ temperatures above $80 \mathrm{~K}, \chi T$ shows a sharp increase for $\mathbf{1}$, which turns into a moderate rise at temperatures above $125 \mathrm{~K}$. Even at RT, the value is only $3.5 \mathrm{~cm}^{3} \mathrm{~K} \mathrm{~mol}^{-1}$ and has not reached the spin-only value expected for a HS iron(III) species $\left(4.4 \mathrm{~cm}^{3} \mathrm{~K} \mathrm{~mol}{ }^{-1}\right)$; no hysteresis was observed upon a subsequent cooling cycle. ${ }^{12}$

Most interestingly, the ac susceptibility data of solid samples of $\mathbf{1}$, measured at zero applied field for frequencies between 10 and $1042 \mathrm{~Hz}$, show a pronounced frequency dependence of the out-of-phase signal (top of Figure 4). The maxima in the $\chi^{\prime \prime}$ vs frequency plot (Figure S4) were extracted into an Arrhenius plot (ln $\tau$ vs $1 / T$ ) and yield a straight line (insert graph in Figure 4, top). Linear fitting resulted in a relaxation time of $\tau_{0}=$ $2 \times 10^{-8} \mathrm{~s}$ and a barrier of $U_{\text {eff }}=32 \mathrm{~cm}^{-1}(47 \mathrm{~K})$, pertaining to this relaxation mechanism, which is assigned to a thermally activated process. The frequency dependence observed in Figure 4 (top) also reveals a second relaxation mechanism that is important below $3 \mathrm{~K}$ or at frequencies below $10 \mathrm{~Hz}$. This is probably due to weak interatomic interactions, and such a phenomenon has not been investigated in detail. Close inspection of the Arrhenius plot indicates a slight curvature that was deemed smaller than the uncertainty in the measured frequency and temperature interval. This feature might reveal the second relaxation regime if lower temperatures and frequencies were to be investigated. The barrier of $U_{\text {eff }}=32$ $\mathrm{cm}^{-1}$ in the thermally activated process calculated from the linear fit is therefore a lower limit. Fitting only the high temperature part of the Arrhenius plot provides $U_{\text {eff }}=36 \mathrm{~cm}^{-1}$ and a relaxation time of of $\tau_{0}=6 \times 10^{-9} \mathrm{~s}$.

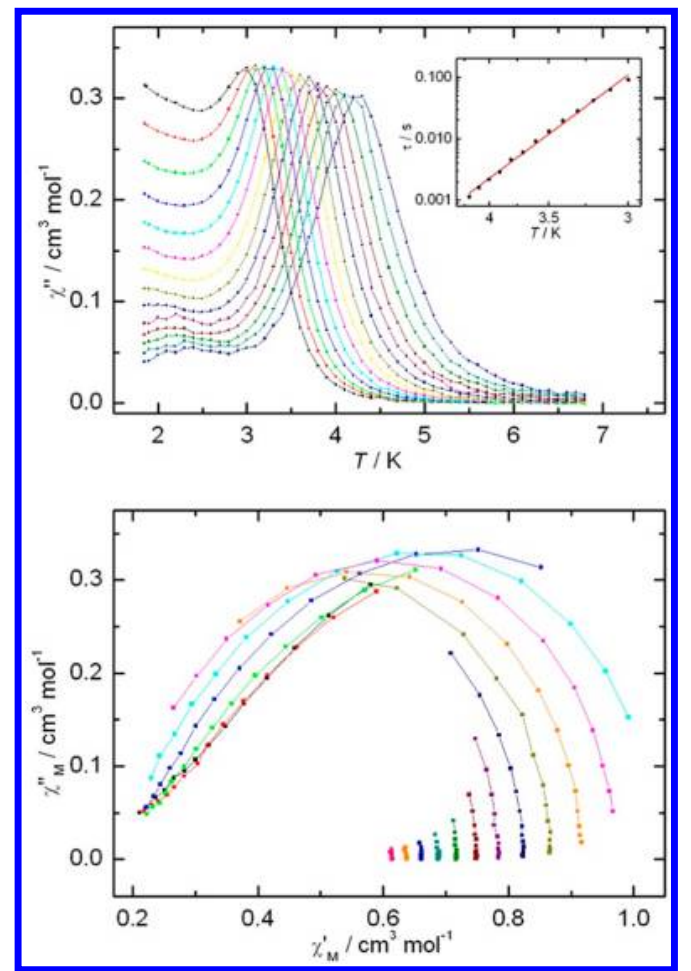

Figure 4. (top) Out-of-phase ac magnetic susceptibility of $\mathbf{1}$ in zero field as a function of temperature at frequencies from $10 \mathrm{~Hz}$ (black) to $1042 \mathrm{~Hz}$ (blue). Insert: Arrhenius plot and linear fit of the maxima. (bottom) Cole-Cole plot of $\mathbf{1}$ at temperatures between $2.2 \mathrm{~K}$ (black) and $6.7 \mathrm{~K}$ (pink).

An extract of the same data are presented as a Cole-Cole plot in the bottom of Figure 4. The most complete curve at 3.7 $\mathrm{K}$ was fitted, and a Cole exponent value $(\alpha)$ of 0.14 was obtained. This is well within the values typically observed for SMM and corresponds to a low deviation from the ideal semicircle. ${ }^{17}$ When an external field of 1500 Oe is applied, essentially the same behavior is observed. ${ }^{12}$ The low-temperature peaks are slightly less pronounced. Complex 2 on the other hand shows no frequency dependence whatsoever of the ac susceptibility in zero applied field. Upon applying an external field of $1500 \mathrm{Oe}$, an onset of frequency dependence of $\chi^{\prime \prime}$ is observed at temperatures below $2.5 \mathrm{~K}$ and frequencies above $100 \mathrm{~Hz}$, but it does not amount to real SMM behavior as is clearly observed for $1 .^{12}$

X-Band EPR Spectroscopic Data. As expected for an axial $S=3 / 2$ system with considerable negative zero field splitting ( $D=-11 \mathrm{~cm}^{-1}$, bottom of Figure 3$)$, the X-band EPR spectrum of 1 in the solid state at $28 \mathrm{~K}$ (Figure 5, top) features a broad resonance line at $g \approx 4$. The EPR signal was measured at 8 different temperatures between 5 and $52 \mathrm{~K}$, with all other experimental parameters kept constant (Figure S11). ${ }^{12}$ The intensity of the $g \approx 4$ line increases with temperature, until a maximum is reached around $28(5) \mathrm{K}$ and then decreases in intensity. Employing an EPR simulation with full matrix diagonalization incorporating both axial zfs and Boltzmann distribution, an estimated $D=-10 \pm 5 \mathrm{~cm}^{-1}$ was obtained from a simulation of the intensity for the spectra obtained below $52 \mathrm{~K}$. Approaching the spin transition temperature, the $g$ $\approx 4$ line broadens and shifts to higher fields. As the temperature is further increased a new line centered at $g=2.03$ intensifies (Figure 5, bottom). In frozen $\mathrm{CH}_{2} \mathrm{Cl}_{2}$ solution at $4 \mathrm{~K}$ an extra single sharp feature at $g \approx 6$ is observed for $1 .{ }^{12}$ For 2 the solid- 


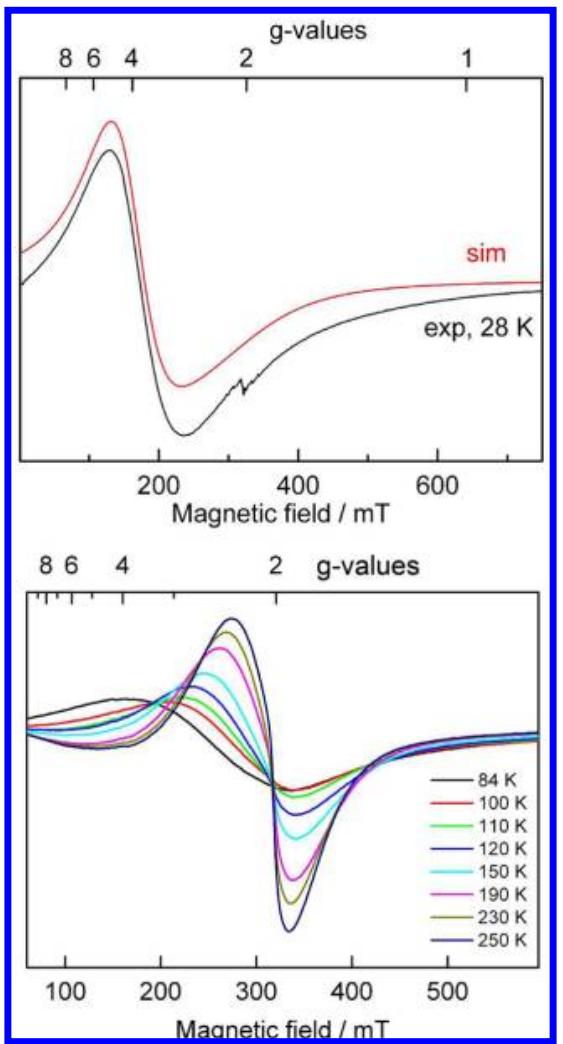

Figure 5. (top) Experimental (black) and simulated (red) X-band EPR spectrum of $\mathbf{1}$ in the solid state at $28 \mathrm{~K}$. The spectrum was simulated using an $S=3 / 2$ spin Hamiltonian with an axial zfs parameter, which is large compared to the microwave frequency. (bottom) Experimental X-band EPR spectra of complex 1 collected between 84 and $250 \mathrm{~K}$.

state spectrum corresponds to a typical undiluted $S=3 / 2$ system with a high zero field splitting and nonzero rhombic splitting $(E / D \sim 0.1)$. The maximum intensity of the line centered at $g \sim 4$ is found below $14 \mathrm{~K}$.

Mössbauer Spectra of [(PNP)FeCl], 1 and 2. The zero field Mössbauer spectrum recorded for $[(\mathrm{PNP}) \mathrm{FeCl}]$ at $77 \mathrm{~K}$ produced a single Mössbauer quadrupole doublet with an isomer shift $\delta$ of $0.72 \mathrm{~mm} \mathrm{~s}^{-1}$ and a quadrupole splitting $\Delta E_{\mathrm{Q}}$ of $1.59 \mathrm{~mm} \mathrm{~s}^{-1}$, consistent with a high spin Fe(II) ion (top of Figure 6). ${ }^{9}$ On the contrary, the parameters observed for complex 1 at $77 \mathrm{~K}$ are $\delta=0.47 \mathrm{~mm} \mathrm{~s}^{-1}$ and $\Delta E_{\mathrm{Q}}=1.56 \mathrm{~mm}$ $\mathrm{s}^{-1}$. For complex 2 the values are $\delta=0.32 \mathrm{~mm} \mathrm{~s}^{-1}$ and $\Delta E_{\mathrm{Q}}=$ $1.98 \mathrm{~mm} \mathrm{~s}^{-1}$ (Figures 6 and 7).

The variable-temperature Mössbauer spectra of $\mathbf{1}$ in zero applied field between 4 and $298 \mathrm{~K}$ are stacked in Figure $7 .{ }^{12}$ At low temperatures, the parameters correspond to an IS Fe(III) species, although the $\delta$ value is high and the $\Delta E_{\mathrm{Q}}$ values are in the lower range for five coordinate IS ferric centers reported in the literature. ${ }^{18,19}$ Due to the second-order Doppler effect, ${ }^{20}$ the isomer shift decreases moderately from 0.47 to $0.36 \mathrm{~mm} \mathrm{~s}^{-1}$ with increasing temperature from 80 to $200 \mathrm{~K}$. However, the quadrupole splitting decreases dramatically from 1.56 to 0.53 $\mathrm{mm} \mathrm{s} \mathrm{s}^{-1}$, Figure 7; see also Figure 2, bottom, where $\Delta E_{\mathrm{Q}}$ is plotted as a function of temperature. At temperatures below 77 $\mathrm{K}$, the relatively broad and asymmetric quadrupole doublet shows magnetic hyperfine splitting, which ultimately resolves at $4 \mathrm{~K}$ into a six-line pattern. The six-line pattern obtained at $4 \mathrm{~K}$ was simulated $^{21}$ using the fixed parameters $D=-11 \mathrm{~cm}^{-1}, g_{\text {iso }}=$ 2.2, $\beta=90^{\circ}, 22$ and the fitted parameters $\delta=0.48 \mathrm{~mm} \mathrm{~s}^{-1}, \Delta E_{\mathrm{O}}$ $=1.77 \mathrm{~mm} \mathrm{~s}^{-1}$, line width $0.32 \mathrm{~mm} \mathrm{~s}^{-1}$, and $A_{\text {iso }}=118 \mathrm{kG}$

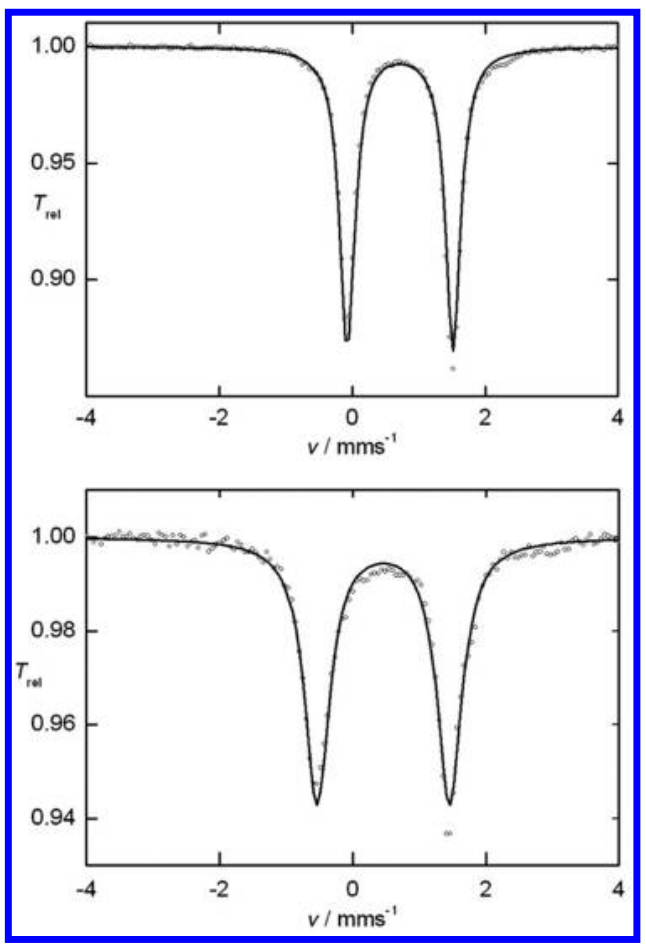

Figure 6. (top) Experimental and simulated zero field Mössbauer spectrum of $[(\mathrm{PNP}) \mathrm{FeCl}]$ at $77 \mathrm{~K}: \delta=0.72 \mathrm{~mm} \mathrm{~s}^{-1}$ and $\Delta E_{\mathrm{Q}}=1.59$ $\mathrm{mm} \mathrm{s}^{-1}$. (bottom) Experimental and simulated zero field Mössbauer spectrum of 2 at $77 \mathrm{~K}: \delta=0.32 \mathrm{~mm} \mathrm{~s}^{-1}$ and $\Delta E_{\mathrm{Q}}=1.98 \mathrm{~mm} \mathrm{~s}^{-1}$.

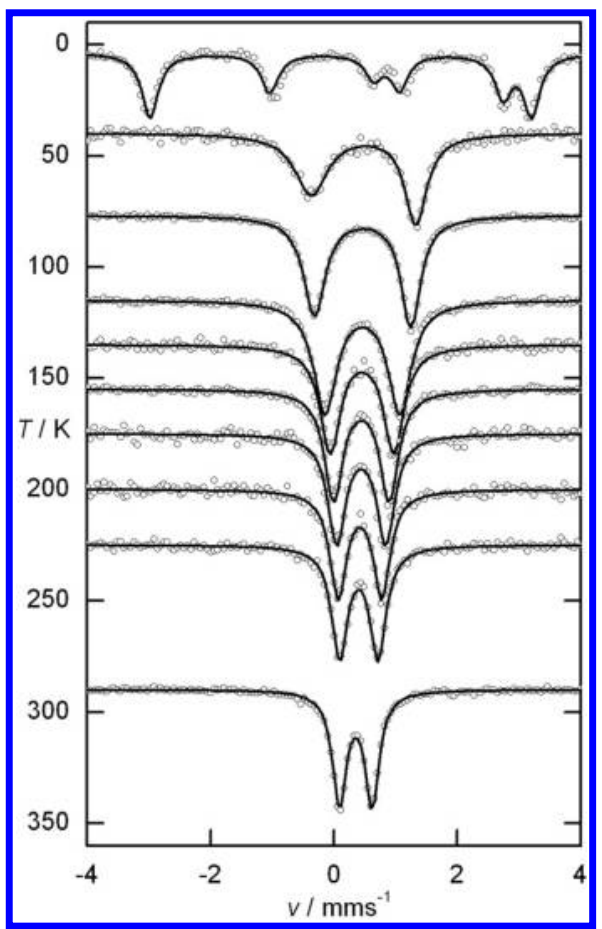

Figure 7. Experimental and simulated zero-field Mössbauer spectra of 1 collected at $4-298 \mathrm{~K}$. The spectrum at $4 \mathrm{~K}$ is simulated using the parameters given in the text.

(Figure 7). It is important to highlight that the resulting parameter set and simulation of the Mössbauer spectra are the only ones found to be consistent with all spectroscopic data at low temperature: SQUID, EPR, and Mössbauer. 


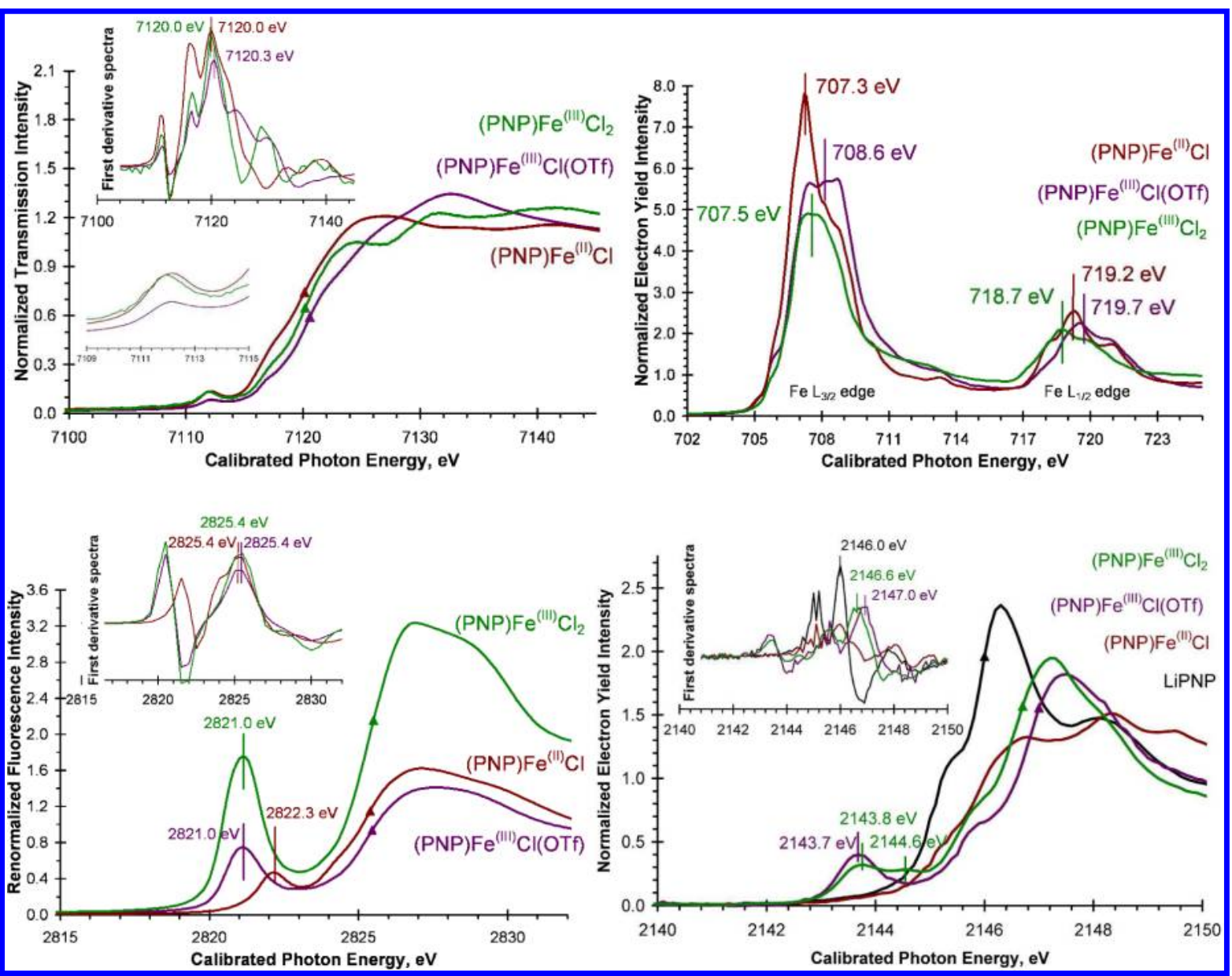

Figure 8. (top left) $\mathrm{Fe} \mathrm{K}$-edge, (top right) $\mathrm{Fe} \mathrm{L}_{3 / 2}$ and $\mathrm{L}_{1 / 2}$-edges, (bottom left) $\mathrm{Cl} \mathrm{K}$-edge, and (bottom right) $\mathrm{P} \mathrm{K}$-edge $\mathrm{XANES}$ spectra of complexes [(PNP) FeCl] (brown), $\mathbf{1}$ (green), and $\mathbf{2}$ (purple).

Multiedge Spectroscopic Measurements of [(PNP)$\mathrm{FeCl}$, 1 and 2. Multiedge X-ray absorption spectroscopic (XAS) measurements at room temperature (Fe K-edge data were collected at $10 \mathrm{~K}$ ) probing the ground-state electronic structure at the $\mathrm{Fe} \mathrm{K}$-, $\mathrm{Fe} \mathrm{L}-, \mathrm{Cl} \mathrm{K}$-, and $\mathrm{P}$ K-edges, corresponding to the $\mathrm{Fe} 1 \mathrm{~s}, \mathrm{Fe} 2 \mathrm{p}, \mathrm{Cl} 1 \mathrm{~s}$, and $\mathrm{P} 1 \mathrm{~s}$ core electron ionization thresholds, respectively, were performed on compounds $\mathbf{1}$ and $\mathbf{2}$ and compared to those observed for the precursor complex $[(\mathrm{PNP}) \mathrm{FeCl}]$. The inset in Figure 8 (top left) shows the first derivative spectra for $[(\mathrm{PNP}) \mathrm{FeCl}], \mathbf{1}$, and 2 , thus indicating overall highly similar effective nuclear charges $\left(Z_{\text {eff }}\right)$ for the Fe centers. A complete one-electron change in the formal $\mathrm{Fe}$ oxidation state would result in up to $6.3 \mathrm{eV}$ shift in the rising edge as can be observed, for example, for ferric and ferrous fluorides, ${ }^{23}$ but $\mathrm{Fe}$-ligand bond covalency and the corresponding ligand-to-metal electron donation in the analogous chloride salts may reduce this value to $\sim 2.1 \mathrm{eV}^{23}$ The differences in pre-edge feature intensities within the energy range of $7110-7114 \mathrm{eV}$ indicate more $\mathrm{Fe} 4 \mathrm{p}$ mixing in complex $\mathbf{1}$ and $[(\mathrm{PNP}) \mathrm{FeCl}]$ vs in complex $\mathbf{2}$. This is the direct result of a more centrosymmetric coordination environment in $\mathbf{2}$ relative to the former compounds that limits the amount of $\mathrm{Fe} 4 \mathrm{p}$ and $3 \mathrm{~d}$ mixing. Despite the covalent nature of $\mathrm{Fe}-\mathrm{Cl}$ and $\mathrm{Fe}-\mathrm{N} /$ $\mathrm{Fe}-\mathrm{P}$ bonds, the $Z_{\text {eff }}(\mathrm{Fe})$ is about $2 \mathrm{eV}$ greater than that of the characteristic tetrahedral ferrous compound $\left[\mathrm{FeCl}_{4}\right]^{2-} \cdot{ }^{23}$ It is notable that the lesser difference in iron oxidation and spin state in 1 vs 2 from Mössbauer spectroscopy relative to
$[(\mathrm{PNP}) \mathrm{FeCl}]$ is reproduced by the $\mathrm{Fe}$ K-edge XANES measurement.

The Fe L-edge spectra in Figure 8 (top right) show more intense features than the $\mathrm{Fe}$ K-edge along and before the ionization edge jumps due to the electric dipole allowed for a $\mathrm{Fe} 2 \mathrm{p} \rightarrow 3 \mathrm{~d}$ transition. The presence of both the $\mathrm{L}_{3 / 2}$ and $\mathrm{L}_{1 / 2}$ edges is due to spin-orbit coupling of the Fe 2p-based corehole, giving $M_{\mathrm{J}}=3 / 2$ and $1 / 2$ final states. The energy positions of the intense pre-edge features display small variations of less than $1 \mathrm{eV}$. However, due to non-negligible multiplet effects for the formally $\mathrm{Fe}(\mathrm{II})$ and $\mathrm{Fe}$ (III) ions, in addition to their largely different coordination environments (especially between [(PNP) $\mathrm{FeCl}]$ and the oxidized forms), the intensity distribution and shape of the pre-edge spectrum differ from each other. The least intense and least structured L-edge feature was measured for complex $\mathbf{1}$, which has the most symmetrical coordination environment. Replacing a chloride with a triflate ligand increases the pre-edge features and slightly shifts up the $\mathrm{Fe} 3 \mathrm{~d}$ manifold due to the reduced $\mathrm{Fe}-\mathrm{O}$ bond covalency relative to $\mathrm{Fe}-\mathrm{Cl}$. The slightly more oxidized $\mathrm{Fe}$ in 2 relative to 1 has also been observed at the Fe K-edge (Figure 8, top left). However, the lack of electron donation from $\mathrm{Cl}$ is compensated by the increased PNP-to-Fe donation via the amide nitrogen. Similarly, in going from 2 to the precursor [(PNP)FeCl] complex the $\mathrm{Fe}$ L-edge intensity increases and redistributes as the bonding and coordination environment changes from fiveto four-coordinate. The energy positions at the Fe L-edge 


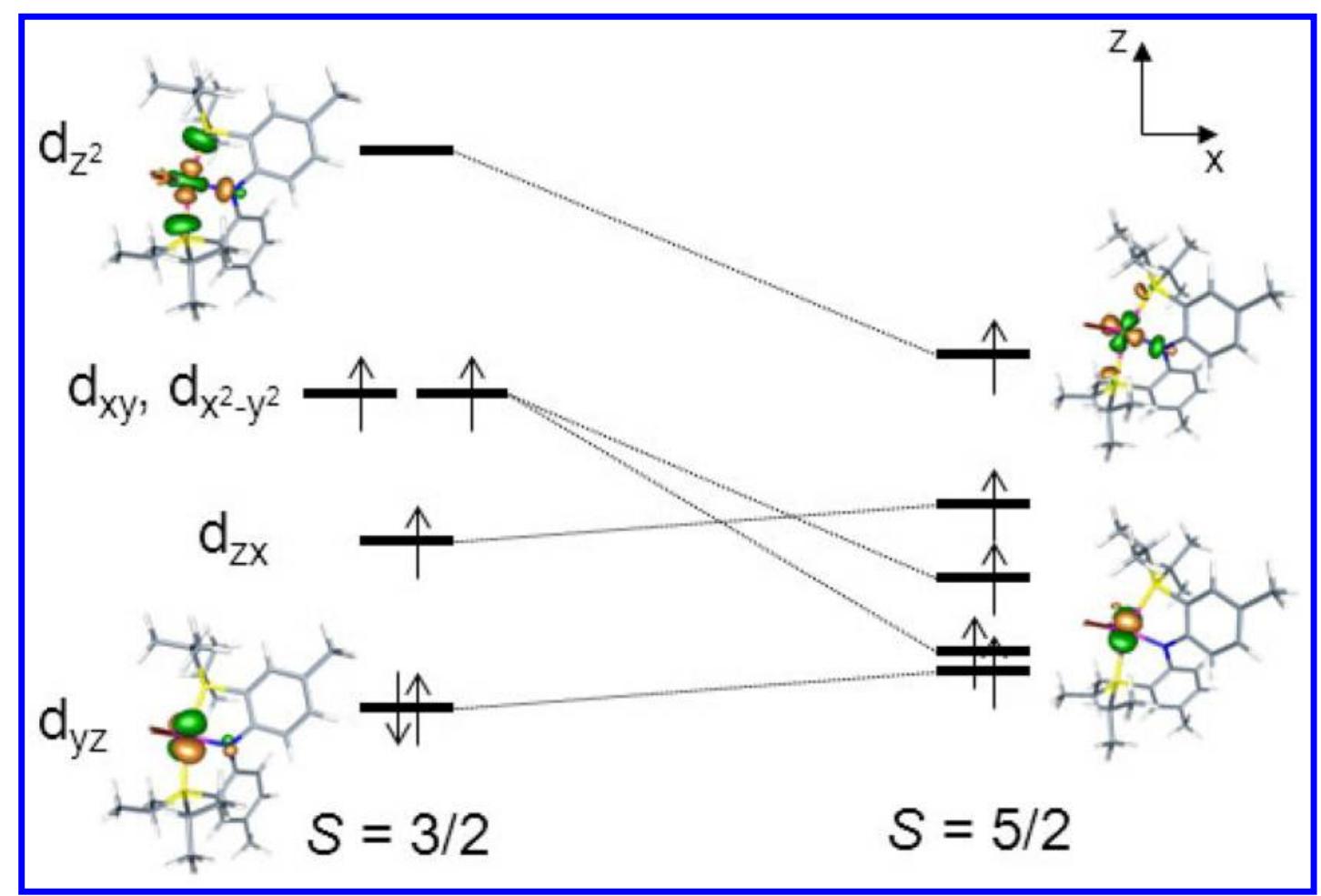

Figure 9. Calculated orbital energy diagram of the IS and HS spin states for 1. Orbital diagrams of quasi-restricted molecular orbitals in the IS and $\mathrm{HS}$ case are shown for the d orbitals that change population during the spin transition.

indicate intensity weighted, pre-edge energy positions, which are indicative of $\mathrm{Fe} Z_{\text {eff }}$ as well as the energy and splitting of the Fe 3d manifold.

The bottom left plot in Figure 8 shows the renormalized $\mathrm{Cl}$ K-edge spectral data that take into account the doubled number of absorbers in $\mathbf{1}$ vs $\mathbf{2}$ and [(PNP)FeCl]. The rising-edge positions of the spectra marked by triangles are within the resolution of this technique $(0.1 \mathrm{eV})$ for this energy range. This indicates that the chloride ligands have approximately identical $Z_{\text {eff }}$ This feature suggests that they maximize their electron donation to the Fe center independently of its formal oxidation state and coordination environment. The mixing of vacant $\mathrm{Fe}$ $3 \mathrm{~d}$ orbitals with $\mathrm{Cl} 3 \mathrm{p}$ orbitals gives rise to the pre-edge features. The approximate change of $1.3 \mathrm{eV}$ higher energy position of the pre-edge feature in complex [(PNP)FeCl] corresponds to a more destabilized, formally ferrous $\mathrm{Fe} 3 \mathrm{~d}$ manifold vs the formally ferric complexes $\mathbf{1}$ and 2 . Since the $\mathrm{Cl}$ rising-edge positions are identical, this shift corresponds to the shift in the Fe d manifold energy due to either increased ligand field splitting or reduced $Z_{\text {eff. }}$ However, as discussed above for the Fe K- and L-edge spectra, this spectral change is mainly due to the change in the ligand field splitting of the Fe $3 \mathrm{~d}$ orbitals as a consequence of their differing coordination geometries. A preedge energy shift of +3.2 and $+2.3 \mathrm{eV}$ is more typical when examining ferric vs ferrous chloride salts in an octahedral and tetrahedral crystal field, respectively. ${ }^{23}$ Specifically, the distorted tetrahedral coordination in $[(\mathrm{PNP}) \mathrm{FeCl}]$ does not allow for as efficient orbital overlap between the $\mathrm{Fe} 3 \mathrm{~d}$ and $\mathrm{Cl} 3 \mathrm{p}$ orbitals as expected for a trigonal bipyramidal structure in $\mathbf{1}$ and $\mathbf{2}$ with the $\mathrm{Cl}^{-}$ligand in the equatorial plane. Using the known $\mathrm{Cl} 1 \mathrm{~s} \rightarrow 3 \mathrm{p}$ transition dipole integral and taking into account the intensity redistribution due to multiplet effects, ${ }^{24}$ the total $\mathrm{Cl}$ covalency per electron hole in 1 can be estimated to be about $41 \%$, compared to $22 \%$ in $[(\mathrm{PNP}) \mathrm{FeCl}]$.
The $\mathrm{Fe}-\mathrm{P}$ bonding has also been directly probed by $\mathrm{P} \mathrm{K}$ edge spectroscopic measurements, and the bottom right spectra of Figure 8 compare the XANES regions for the $\mathrm{Li}(\mathrm{PNP})$ salt, [(PNP)FeCl], and complexes 1 and 2 . The shift in the most intense feature or white-line, which is attributed to the $\mathrm{C}-\mathrm{P} \sigma^{*}$ bonds, is indicative of considerable electron donation from the $\mathrm{P}$ ligand to the metal centers. This parallels the changes in the rising-edge inflection points (2146.0, 2146.6, and $2147.0 \mathrm{eV}$ ), as indicated by the first resolved maximum along the risingedge (see inset in bottom right of Figure 8) and the solid triangles in the spectra. Similarly to the $\mathrm{Cl} \mathrm{K}$-edge spectra (bottom left of Figure 8), the appearance of pre-edge features is the direct indication of covalent mixing of Fe $3 \mathrm{~d}$ and P $3 p$ orbitals. While these features are well resolved in both $\mathrm{Fe}(\mathrm{III})$ complexes due to the lower metal effective nuclear charge in $\mathrm{Fe}(\mathrm{II})$, no pre-edge feature was detected for the [(PNP)FeCl] complex, similar to the ferrous vs ferric thiolates. ${ }^{25}$ The higher energy position of the rising-edge inflection point for $\mathbf{2}$ is also consistent with the larger pre-edge feature at $2143.7 \mathrm{eV}$ vs the corresponding one at $2143.8 \mathrm{eV}$ in $\mathbf{1}$. Furthermore, this is also expected from replacing a good donor $\mathrm{Cl}^{-}$ligand in $\mathbf{1}$ with a poor donor $\mathrm{TfO}^{-}$ligand in 2 and thus the $\mathrm{P} \rightarrow \mathrm{Fe}$ donation is enhanced in the latter vs the former.

Theoretical Studies of Complex 1. Relative energies of the IS and HS states were calculated using the ORCA program package with B3LYP functional and Ahlrich-TZV basis set on complex 1 without any structural truncations. Both spin states were investigated using single-point calculations on the corresponding geometry optimized molecules. ${ }^{26}$ The computational analysis predicts the sextet state, ${ }^{6} \mathrm{~A}$, to be slightly more stable than the quartet state, ${ }^{4} \mathrm{~B}$ (point group $C_{2}$ ). The calculated bond distances in both spin states have been compared to the values determined by X-ray crystallography at 30 and $300 \mathrm{~K}$ and are shown in Table 1. The geometric 
differences between the two spin states are expressed by an opening of the pincer ligand ( $\mathrm{Fe}-\mathrm{P}$ distance increased by $10 \%$ ) and a further twist of the angle between the aromatic rings (14\%), which will change the $\pi$-donor characteristics of the amido nitrogen. However, since $\pi$ donation of the amide is minimal, the $\mathrm{Fe}-\mathrm{N}$ distances stay relatively similar, which is corroborated by the VT X-ray structural study (Table 1). The single crystal X-ray structure at $150 \mathrm{~K}$ (Table 1) shows metrical parameters that are consistently between the calculated values for IS and HS (but leaning closer to the IS state). However, the metrical parameters at $30 \mathrm{~K}$ are clearly more consistent with the IS state, while the high-temperature structure at $300 \mathrm{~K}$ lies closer to the HS state. As observed in the VT single crystal structure study, the $\mathrm{Fe}-\mathrm{P}$ increases from IS to HS, contrary to the $\mathrm{Fe}-\mathrm{Cl}$ distance (Table 1). For the IS structure, the optimized geometry shows a larger $\mathrm{P}-\mathrm{Fe}-\mathrm{P}$ angle, which decreases when shifting to the HS state. Consequently, the $\mathrm{Cl}-$ $\mathrm{Fe}-\mathrm{Cl}$ angle for the IS state of $\mathbf{1}$ is much smaller than for the HS state (Table 1).

Using the geometry optimized structure, we computed the frontier orbitals for the IS and HS states of complex 1. In Figure 9, the LUMO for the IS state of complex 1 can be easily recognized as a $\mathrm{d}\left(z^{2}\right)$ orbital having $\sigma$-interaction with the phosphine ligands. The doubly occupied MO of the IS is of $\mathrm{d}(y z)$ parentage. For the HS state of complex 1 the energy difference between the metal based $d$ orbitals is minimized with the $\mathrm{d}\left(z^{2}\right) \sigma^{*}$ MO now being half-filled due to substantial stabilization. Despite the $\mathrm{d}(x y)$ and $\mathrm{d}\left(x^{2}-y^{2}\right)$ orbitals becoming more stabilized, most MO's remain overall similar. The Mössbauer parameters of 1 were calculated to be $\Delta E_{\mathrm{Q}}=$ $2.35 \mathrm{~mm} \mathrm{~s}^{-1}$ for the quartet and $1.35 \mathrm{mms}^{-1}$ for the sextet state. Both values are thus estimated to be higher than the experimental values at $40 \mathrm{~K}$ and RT assigned to an IS and a predominantly HS spin state, respectively $(1.70$ and $0.53 \mathrm{~mm}$ $\mathrm{s}^{-1}$ ), although a lower $\Delta E_{\mathrm{Q}}$ for the higher spin state is predicted by our theoretical investigation. The electronic field gradient tensor in the quartet state is calculated to be oriented along the $\mathrm{Fe}-\mathrm{N}$ bond. Shown in Figure 9 is the orbital lobe on the $\mathrm{Cl}$ atom which corresponds to the XAS pre-edge intensity at the $\mathrm{Cl}$ K-edge shown in the bottom of Figure 8 . Such small differences among the energy positions of the pre-edge features parallel the calculated small energy differences in the orbital levels.

\section{DISCUSSION}

Spin-crossover from IS to $\mathrm{HS}$ in mononuclear $\mathrm{Fe}(\mathrm{III})$ complexes is a rare phenomenon. ${ }^{27}$ In general, low spin (LS, $S=1 / 2$ ) to HS spin transitions have been observed for sixcoordinate $\mathrm{Fe}(\mathrm{III})$ complexes, while quantum mechanically admixed HS and IS states are more often observed for fivecoordinate $\mathrm{Fe}(\mathrm{III}) .^{28}$ The spin state of the latter can depend on the donor capability of a single axial ligand in $\mathrm{N}_{4} \mathrm{X}$ ligand environments. $^{29,30}$ For some porphyrin $\mathrm{Fe}(\mathrm{III})$ compounds with weak axial ligands, ${ }^{31}$ a gradual increase in the magnetic moment and a single quadrupole doublet are taken as evidence for a quantum mechanically admixed state rather than a legitimate spin transition. ${ }^{32}$ In our study, the dc susceptibility traces are dissimilar to the ones of typical spin admixed compounds but follow closely the structural parameters. The out-of-phase ac magnetic susceptibility study shown in Figure 4 (top) is clear evidence for single molecular magnetism and, to the best of our knowledge, an unparalleled behavior for iron in the absence of an applied magnetic field. Surprisingly, this behavior contrasts the close derivative, 2 , which shows a more typical IS pattern between 25 and $300 \mathrm{~K}$ and only the barest hint of slow relaxation of the magnetization in an applied magnetic field. ${ }^{12}$ The X-band EPR spectra of $\mathbf{1}$ are as expected for $S=3 / 2$ with large negative axial zfs in the solid state at low temperatures. Examining the solid-state EPR spectrum of 1 (Figure 5, bottom) reveals a new line at $g=2$ from the thermally populated state at temperatures above the transition temperature, but this signal is clearly not typical for ferric $S=$ $5 / 2$ spectra. Usually for an $S=5 / 2$ system with high axial $\mathrm{zfs,}$ the spectrum contains a sharp feature at $g \approx 6 .{ }^{33}$ This signal centered at $g=2.03$ for $\mathbf{1}$ is more alike to a formally ferric $S=$ $1 / 2$ species, but considering the magnetization, Mössbauer, and XAS data, it could also indicate that the new species obtained at high temperatures has small zfs compared to the microwave energy $\left(0.3 \mathrm{~cm}^{-1}\right)$ due to delocalization onto the ligands vide infra. In frozen $\mathrm{CH}_{2} \mathrm{Cl}_{2}$ solution the very low temperature $\mathrm{X}$ band EPR spectral data are unalike. At $4 \mathrm{~K}$ we observe an additional sharp line at $g=6.5$ not observed in the solid state. ${ }^{12}$ The spectrum and temperature dependence in solution are very similar to the solution spectrum reported by Ohgo et al. for a saddled iron porphyrin ${ }^{33 a}$ where it was assigned to an axial $S=$ $5 / 2$ species being present at low temperature.

To make matters more complicated, the previously described noninnocent behavior of the PNP ligand ${ }^{34}$ is likely important in the HS state, and the multiedge XAS data indicate remarkably small energy differences for the Fe K-edge spectral features as a result of increase in formal oxidation state and coordination numbers. The large electron donation from the $\mathrm{Cl}$ ligand is an indication for the availability of good orbital overlap for efficient ligand-to-metal charge transfer in $\mathbf{1}$ and $\mathbf{2}$. When modeling the magnetization and EPR data of complex 1 at temperatures below $80 \mathrm{~K}$, we have used a spin Hamilton model with $S=3 / 2$ and obtained good fits utilizing a strong uniaxial anisotropy expressed by an axial zfs of $D=-11(3) \mathrm{cm}^{-1}$ and a rhombic zfs parameter $E=0$ within the uncertainty. Applying this model, the closest lying state should be $|2 D|=22 \mathrm{~cm}^{-1}$ away which is smaller than the barrier of spin reversal found in the Arrhenius plot $\left(32-36 \mathrm{~cm}^{-1}\right)$. This discrepancy is unprecedented because the values of the barriers in Arrhenius plots of molecular magnets are usually found to be much smaller than those of the theoretical barriers calculated from $\mathrm{zfs}$ parameters. ${ }^{6-8}$ Even though our fit of the magnetization and EPR data to the spin Hamiltonian model gave quite good fits, we recognize the pitfalls in using experimental data that are relatively insensitive to the value of the $\mathrm{zfs}$ parameter $D$. It should be noted that both methods predict the same value though. The spin transition taking place at higher temperatures in $\mathbf{1}$ suggests to us that the HS state is mixed into the ground state in a situation which might be akin to the quantum mechanically admixed ground state invoked by Maltempo to describe iron(III) porphyrin systems with moderate field axial ligands. ${ }^{32}$ Porphyrin systems with weaker axial ligands are generally reported to have considerably positive $\mathrm{zfs}$ values. ${ }^{35}$ On the other hand, complex 1 presents the opposite situation in the ligand field sense: Here the axial ligands are strong donors, and the equatorial ligands are weaker leading to a substantial negative axial zfs parameter and quite conceivably, its SMM properties.

The isomer shift observed in the Mössbauer spectrum of the precursor complex $[(\mathrm{PNP}) \mathrm{FeCl}]$ is in accord with a fourcoordinate ferrous ion and resembles that of a pseudotetrahedral $\mathrm{Fe}(\mathrm{II})-\mathrm{S}_{4}$ site in iron-sulfur clusters $(\delta=0.72 \mathrm{~mm}$ $\left.\sec ^{-1}\right) \cdot{ }^{36} \mathrm{~A}$ significant shift in $\delta$-value would invoke an increase 
in oxidation state of the iron center. In the case of complexes 1 and 2 , oxidation of the $3 \mathrm{~d}$ shell in iron results in an increase in the s electron density at the iron nucleus, and the $\delta$ value shifts negatively due to $\delta \mathrm{R} / \mathrm{R}$ for ${ }^{57} \mathrm{Fe}$ nucleus. Hence, the Mössbauer data are consistent with at least some degree of oxidation at the metal center, which is more in accord with an intermediate spin ferric center for complexes 1 and 2. Complex 1 does, however, show significant temperature dependence in $\delta$ and $\Delta E_{\mathrm{Q}}$ values, which is in agreement with the system undergoing a change in spin state (Figures 2 (bottom), 7, and S1). ${ }^{12}$ Overall, the observed transition into a magnetically ordered state on the Mössbauer time scale clearly corroborates the slow relaxation on the slower ac susceptibility time scale. Complex 1 only shows one quadrupole doublet in the Mössbauer spectra at all temperatures above $4 \mathrm{~K}$, which implies the mixing of states rather than a transition between two distinct spin states.

The structural changes observed with decreasing temperature make the strong donors interact stronger on the destabilized $\mathrm{d}\left(z^{2}\right)$ orbital, and we currently believe the structural change to be dominating the spin transition (Figure 2, bottom). To establish whether the ligands in the oxidized complexes $\mathbf{1}$ and $\mathbf{2}$ are "redox innocent", we relied on multiedge X-ray absorption spectra and, for comparison, also investigated precursor $[(\mathrm{PNP}) \mathrm{FeCl}]$. Since the rising edge positions of the $\mathrm{Fe} \mathrm{K}$ edge spectra are most sensitive to the effective nuclear charge $\left(Z_{\text {eff }}\right)$ of the Fe centers, which is commonly estimated from the rising-edge inflection points, the spectra can provide an experimental measure of what the effective oxidation state or simply the charge of the $\mathrm{Fe}$ ion should be. The Fe K-edge XANES spectra shown in Figure 8 (top left) reveal peaks for $[(\mathrm{PNP}) \mathrm{FeCl}], \mathbf{1}$, and $\mathbf{2}$ at around $7120 \mathrm{eV}$, which are in between the $Z_{\text {eff }}(\mathrm{Fe})$ of ferrous $(7119.5 \mathrm{eV})$ and ferric $(7121.6$ $\mathrm{eV}$ ) chlorides. The Fe L-edge XAS data on the other hand provide a direct experimental handle to evaluate the ligand field splitting of $\mathrm{Fe} 3 \mathrm{~d}$ manifold and orbital composition in addition to being a less sensitive probe of $Z_{\text {eff }}(\mathrm{Fe})$. However, since we know that the $Z_{\text {eff }}(\mathrm{Fe})$ is relatively constant for all complexes, we can use the changes in the Fe L-edge spectra of Figure 8 (top right) as a direct measure of changes in the Fe 3d orbitals. The intensities of the Fe L-edge pre-edge features in Figure 8 (top right) are overall similar to the reference $\mathrm{Fe}(\mathrm{II}) / \mathrm{Fe}$ (III) chloride spectra with covalent $\mathrm{Fe}-\mathrm{Cl}$ bonds ${ }^{12}$ that indicate a considerable degree of ligand-to-metal donation in parallel with the analysis of the corresponding Fe K-edge spectra. Likewise, the $\mathrm{Cl} \mathrm{K-edge} \mathrm{spectral} \mathrm{data} \mathrm{suggest} \mathrm{a} \mathrm{significant} \mathrm{degree} \mathrm{of}$ covalency for the $\mathrm{Fe}-\mathrm{Cl}$ bonds in complexes $\mathbf{1}$ and $\mathbf{2}$ when compared to precursor $[(\mathrm{PNP}) \mathrm{FeCl}]$. Therefore, these results imply that oxidation of complex $[(\mathrm{PNP}) \mathrm{FeCl}]$ is initially metal based (as expected for a coordination compound with a highly covalent but normal bonding description), but upon coordination of a poor donor, such as ${ }^{-} \mathrm{OTf}$, the iron coordination geometry changes. Hence, when going from a distorted tetrahedral to trigonal bipyramidal a new set of orbital overlap is formed that facilitates efficient ligand-to-metal electron donation and results in covalent coordination compounds. In comparison to other PNP pincer-type complexes with documented inverted bonding scheme and noninnocent behavior, ${ }^{34}$ the intensities of the pre-edge features are indicative of covalent but not inverted $\mathrm{Fe}-\mathrm{P}$ bonding (bottom right of Figure 8). Due to the current data quality and limited knowledge of the specific $\mathrm{P} 1 s \rightarrow 3 \mathrm{p}$ transition dipole integral, more quantitative data analysis is not possible to carry out. However, it is important to realize the difference between the two formally ferric complexes. While 2 has only one resolved feature at $2141.7 \mathrm{eV}$, complex 1 features two pre-edges at 2141.8 and $2142.6 \mathrm{eV}$. This is consistent with the molecular orbital pictures discussed for the two different spin states. The IS state has an unoccupied $\mathrm{d}\left(z^{2}\right)$ orbital with large $\mathrm{P}$ contributions, which diminishes and redistributes among all Fe 3d orbitals in the HS state. Thus, from P K-edge XAS data we can assign the spin states at room temperature for $\mathbf{1}$ and $\mathbf{2}$ to be $S=5 / 2$ and $3 / 2$, respectively.

$\mathrm{X}$-ray diffraction studies of a single crystal of $\mathbf{1}$ at five different temperatures $(30-300 \mathrm{~K})$ lend irrefutable support to geometrical distortions resulting in the quartet to sextet spin transition. The most salient structural features include an increment in the $\mathrm{Fe}-\mathrm{P}$ distances by more than $1 / 10$ of an $\AA$. On the other hand, the $\mathrm{Fe}-\mathrm{Cl}$ distances decrease, while the $\mathrm{Fe}-\mathrm{N}$ distances increase, but only moderately by a $\sim 1 / 50$ of $\AA$. Although the $\mathrm{P}-\mathrm{Fe}-\mathrm{P}$ angle decreases by only $\sim 2^{\circ}$, the $\mathrm{Cl}-$ $\mathrm{Fe}-\mathrm{Cl}$ angle increases by almost $6^{\circ}$. Most impressively, these structural changes have been reproduced theoretically for the purely HS and IS variants of $\mathbf{1}$. The significant elongation of the $\mathrm{Fe}-\mathrm{P}$ distances is intuitively expected for the HS system since the $\mathrm{d}\left(z^{2}\right) \sigma^{*}$ orbital pointing along the $\mathrm{P}-\mathrm{Fe}-\mathrm{P}$ axis is now half-filled. Based on $\mathrm{C}-\mathrm{C}$ or $\mathrm{C}-\mathrm{N}$ distances, the $\mathrm{X}$-ray data for complex 1 do not display any evidence of radical behavior of the PNP ancillary. Theoretical studies also predict the $\mathrm{d}\left(z^{2}\right)$ orbital to be highly affected during the spin transition, becoming more stabilized when shifting from IS to HS. The $\mathrm{d}$ orbital splitting diagram also predicts the $\mathrm{d}(x y)$ and $\mathrm{d}\left(x^{2}-\right.$ $\left.y^{2}\right)$ orbitals to be stabilized in the HS system, with the $\mathrm{d}(x z)$ and $\mathrm{d}(y z)$ being relatively unperturbed when shifting from IS to HS. Pronounced development in the $\mathrm{Cl}-\mathrm{Fe}-\mathrm{Cl}$ angle is most likely the result of the chloride ligands avoiding direct overlap with the $\mathrm{d}\left(z^{2}\right)$ orbital which is now filled and has shifted donor character along the $x$ axis compared to the empty orbital in the IS state (Figure 9). We find theoretically that the HS state is lower in energy but with an energy difference of merely 38 $\mathrm{cm}^{-1}$ at the B3LYP/TZVP level of theory. The fact that $\mathrm{d}\left(z^{2}\right)$ is the LUMO for an IS system clearly sets 1 apart from typical IS $\mathrm{Fe}(\mathrm{III})$ compounds, where the empty orbital has more $\mathrm{d}\left(x^{2}-\right.$ $\left.y^{2}\right)$ character. ${ }^{37-39}$

\section{CONCLUSIONS}

The unprecedented coordination environment for $\mathbf{1}$ with strong axial and weaker equatorial donors precludes us from comparing our findings with other examples in the literature (if any). The combination of $\mathrm{dc}$ and ac magnetic susceptibility measurements, Mössbauer, and EPR spectroscopy provides strong evidence of a predominantly $S=3 / 2$ ground state below $50 \mathrm{~K}$ in the solid state, whereas the single quadrupole doublet at higher temperatures indicates a higher degree of mixing taking place between excited states. The nonlinear structural changes accompanying the spin transition are strongly correlated with the spectroscopic results (Figure 2, bottom). Based on the different temperature-dependent studies, we argue that the structural changes are completely controlling the admixture of states throughout the spin transition. The redox noninnocent nature of the ancillary ligands complicates the elucidation of the electronic structure. Based on the $\mathrm{Cl}$ and $\mathrm{P}$ $\mathrm{K}$-edge spectral data for $\mathrm{1}$, the $\mathrm{Fe}-\mathrm{Cl}$ and $\mathrm{Fe}-\mathrm{P}$ bonds have a high degree of covalency. There is also a similar degree of covalency in the $\mathrm{Fe}-\mathrm{P}$ bond as implied by the Fe L-edge data. Likewise, the Fe K-edge XANES spectral data suggest the $\mathrm{Fe}$ center in complexes $\mathbf{1}$ or $\mathbf{2}$ to be intermediate between ferric 
and ferrous, and thus the oxidation chemistry is not purely metal- or ligand-based.

The novel magnetic properties shown by the mononuclear complex 1 are that of an unprecedented single molecule magnetism for iron(III). Notably, this property is exerted by a single d-block metal center at low temperature and a novel spin transition above $80 \mathrm{~K}$. As others before us, we find that the zfs parameter $D$ obtained from susceptibility measurements provides us with a poor estimate of the relaxation barrier $\left(\sim 22 \mathrm{~cm}^{-1}\right)$. Unlike for other single center SMM systems, however, we find that the observed relaxation barrier of at least $32 \mathrm{~cm}^{-1}$ in the Arrhenius plot is larger than the prediction from the theoretical $S=3 / 2$ spin Hamiltonian model. This suggests to us that the spin Hamiltonian model is too simplified for this system, even in the low temperature region. The ground state is not purely $S=3 / 2$ but rather a quantum mechanically admixed state with the close lying excited $S=5 / 2$ state mixing in through the action of spin-orbit coupling. This feature could indeed cause the splitting of the ground state to be larger than predicted by the spin Hamiltonian. Another surprising point is the late onset of quantum tunneling of the magnetization. Unlike the other single center SMM, such as the reported $\mathrm{Fe}(\mathrm{II})(S=2)^{6,7}$ or cobalt(II) $(S=3 / 2)$ systems, $^{8}$ complex 1 displays an unprecedented and almost perfectly linear Arrhenius plot in the frequency interval 10-1042 Hz. The reason for this is not presently clear, and indeed the similar compound 2 does not show any SMM behavior under zero applied field. The different factors expected to be important are the following: (i) The interatomic Fe $\cdots$ Fe distance of $\sim 9.5 \AA$ in 1 must be enough to provide well-isolated spin centers; (ii) the half-integer spins are expected to decrease the tunneling probability through the barrier; (iii) the spin admixture in the ground state must be important in providing a higher $D$ value $\left(\sim 11 \mathrm{~cm}^{-1}\right.$ for 1 compared to $-6 \mathrm{~cm}^{-1}$ for 2$)$; (iv) the resulting poor quantum numbers in the ground-state multiplet might have an additional detrimental effect on the tunneling probability due to the violation of selection rules in the $C_{2}$ symmetry. ${ }^{40}$ Compound 2 on the other hand has lower $\mathrm{zfs}$ and lower symmetry and lacks the pronounced quantum mechanical admixture of states, thus preventing it from displaying true SMM behavior at low temperature. Fortunately, the small size of the magnetic system will allow the single molecule magnetism and spin transition to be investigated more thoroughly with first-principle theoretical methods.

\section{ASSOCIATED CONTENT}

\section{S Supporting Information}

Experimental procedures, X-ray crystallographic information CCDC-870797 (for $\mathbf{1}$ at $30 \mathrm{~K}$ ), CCDC-870798 (for $\mathbf{1}$ at 100 $\mathrm{K}$ ), CCDC-870799 (for $\mathbf{1}$ at $150 \mathrm{~K}$ ), CCDC-870800 (for $\mathbf{1}$ at $200 \mathrm{~K}$ ), CCDC-870801 (for 1 at $250 \mathrm{~K}$ ), and CCDC-870802 (for $\mathbf{1}$ at $300 \mathrm{~K}$ ), additional plots of magnetization and EPR data, full documentation of XAS spectral data, and calculation details are provided. This material is available free of charge via the Internet at http://pubs.acs.org.

\section{AUTHOR INFORMATION}

\section{Corresponding Author}

slmo@kemi.dtu.dk; Karsten.Meyer@chemie.uni-erlangen.de; mindiola@indiana.edu

\section{Notes}

The authors declare no competing financial interest.

\section{ACKNOWLEDGMENTS}

Financial support of this research was provided by Chemical Sciences, Geosciences, and Biosciences Division, Office of Basic Energy Science, Office of Science, U.S. Department of Energy (no. DE-FG02-07ER15893). D.J.M. thanks Dr. Falguni Basuli, Dr. Marco G. Crestani, Dr. Richard Lord, and Professor Paul Müller for insightful discussions and the Alexander von Humboldt Stiftung for support through a Friedrich Bessel Research Award. K.M. and S.M. wish to thank the Deutsche Forschungsgemeinschaft (DFG SFB 583) and the University of Erlangen for financial support. S.M. acknowledges funding from the Danish Council for Independent Research: Technology and Production. Portions of this research were carried out at the Stanford Synchrotron Radiation Lightsource, a Directorate of SLAC National Accelerator Laboratory and an Office of Science User Facility operated for the U.S. Department of Energy Office of Science by Stanford University. The SSRL Structural Molecular Biology Program is supported by the DOE Office of Biological and Environmental Research and by the National Institutes of Health, National Center for Research Resources, Biomedical Technology Program (P41RR001209). Phosphorus K-edge XANES spectra were performed at the Canadian LightSource, which is supported by the Natural Sciences and Engineering Research Council of Canada, the National Research Council Canada, the Canadian Institutes of Health Research, the Province of Saskatchewan, Western Economic Diversification Canada, and the University of Saskatchewan.

\section{REFERENCES}

(1) Leuenberger, M. N.; Loss, D. Nature 2001, 410, 789. (b) Bogani, L.; Wernsdorfer, W. Nat. Mater. 2008, 7, 179. (c) Evangelisti, M.; Luis, F.; de Jongh, L. J.; Affronte, M. I. Mater. Chem. 2006, 16, 2534.

(2) Sessoli, R.; Tsai, H. L.; Schake, A. R.; Wang, S.; Vincent, J. B.; Folting, K.; Gatteschi, D.; Christou, G.; Hendrickson, D. N. J. Am. Chem. Soc. 1993, 115, 1804.

(3) Sessoli, R.; Gatteschi, D.; Caneschi, A.; Novak, M. A. Nature 1993, 365, 141.

(4) Wernsdorfer, W.; Sessoli, R. Science 1999, 284, 133.

(5) (a) AlDamen, M. A.; Clemente-Juan, J. M.; Coronado, E.; MartíGastaldo, C.; Gaita-Ariño, A. I. Am. Chem. Soc. 2008, 130, 8874. (b) Jiang, S.-D.; Wang, B.-W.; Su, G.; Wang, Z.-M.; Gao, S. Angew. Chem., Int. Ed. 2010, 49, 7448. (c) Rinehart, J. D.; Long, J. R. J. Am. Chem. Soc. 2009, 131, 12558. (d) Jeletic, M.; Lin, P.-H.; Le Roy, J. J.; Korobkov, I.; Gorelsky, S. I.; Murugesu, M. J. Am. Chem. Soc. 2011, 133, 19286.

(6) (a) Freedman, D. E.; Harman, W. H.; Harris, T. D.; Long, G. J.; Chang, C. J.; Long, J. R. I. Am. Chem. Soc. 2010, 132, 1224. (b) Harman, W. H.; Harris, T. D.; Freedman, D. E.; Fong, H.; Chang, A.; Rinehart, J. D.; Ozarowski, A.; Sougrati, M. T.; Grandjean, F.; Long, G. J.; Long, J. R.; Chang, C. J. J. Am. Chem. Soc. 2010, 132, 18115 .

(7) (a) Lin, P.-H.; Smythe, N. C.; Gorelsky, S. I.; Maguire, S.; Henson, N. J.; Korobkov, I.; Scott, B. L.; Gordon, J. C.; Baker, R. T.; Murugesu, M. I. Am. Chem. Soc. 2011, 133, 15806. (b) Weismann, D.; Sun, Y.; Lan, Y.; Wolmershäuser, G.; Powell, A. K.; Sitzmann, H. Chem.-Eur. I. 2011, 17, 4700.

(8) (a) Zadrozny, J. M.; Long, J. R. I. Am. Chem. Soc. 2011, 133, 20732. (b) Jurca, T.; Farghal, A.; Lin, P.-H.; Korobkov, I.; Murugesu, M.; Richeson, D. S. I. Am. Chem. Soc. 2011, 133, 15814.

(9) Adhikari, D.; Basuli, F.; Fan, H.; Huffman, J. C.; Pink, M.; Mindiola, D. I. Inorg. Chem. 2008, 47, 4439.

(10) Kern, R. J. I. Inorg. Nucl. Chem. 1962, 24, 1105.

(11) (a) Fout, A. R.; Basuli, F.; Fan, H.; Tomaszewski, J.; Huffman, J. C.; Baik, M.-H.; Mindiola, D. I. Angew. Chem. Int. Ed. 2006, 45, 3291. 
(b) Lankamp, H.; Nanta, W. Th.; MacLean, C. Tetrahedron Lett. 1968, 9, 249.

(12) See Supporting Information.

(13) Bailey, B. C.; Basuli, F.; Huffman, J. C.; Mindiola, D. J. Organometallics 2006, 25, 2725-2728.

(14) $\left[\mathrm{FeCp}_{2}\right][\mathrm{OTf}]$ is used as the limiting reagent given the solubility of the $\mathrm{Fe}(\mathrm{II})$ precursor [(PNP) $\mathrm{FeCl}]$, ref 12 .

(15) $\tau$ is defined as $(A-B) / 60$, with $A$ and $B$ being the largest and the smallest ligand-metal-ligand angles in the base of the approximate square pyramid, where $\tau=0$ for square planar and $\tau=$ 1 for tbp coordination.

(16) Swenson, D.; Baenziger, N. C.; Coucouvanis, D. J. Am. Chem. Soc. 1978, 100, 1932.

(17) Gatteschi, D.; Sessoli, R.; Villain, J. In Molecular Nanomagnets; Oxford University Press: Oxford, U.K., 2006.

(18) Ray, K.; Bill, E.; Weyhermüller, T.; Wieghardt, K. J. Am. Chem. Soc. 2005, 127, 5641-5654.

(19) Gütlich, P., Bill, E.; Trautwein, A. X. Mössbauer Spectroscopy and Transition Metal Chemistry; Springer: Berlin, 2011.

(20) (a) In Chemical Mössbauer Spectroscopy; Herber, R. H., Ed.; Plenum: New York, 1984. (b) Yousif, A. A.; Winkler, H.; Toftlund, H.; Trautwein, A. X.; Herber, R. H. L. Phvs.: Condens. Matter 1989, 1, 7103.

(21) Bill, E. MX: Mössbauer Fit and Simulation Program; MPI für Bioanorganische Chemie: Mülheim an der Ruhr, Germany, 2007.

(22) $\beta$ is the angle between the magnetic anisotropy axis (zfs axis) and the electronic field gradient axis.

(23) Westre, T. E; Kennepohl, P.; DeWitt, J. G.; Hedman, B.; Hodgson, K. O.; Solomon, E. I. I. Am. Chem. Soc. 1997, 119, 6297.

(24) Shadle, S. E.; Hedman, B.; Hodgson, K. O.; Solomon, E. I. J. Am. Chem. Soc. 1995, 117, 2259.

(25) Williams, K. R.; Hedman, B.; Hodgson, K. O.; Solomon, E. I. Inorg. Chim. Acta 1997, 263, 315.

(26) Neese, F. ORCA: $A n$ Ab Initio, Density Functional and Semiempirical Program Package, version 2.7; Institut für Physikalische und Theoretische Chemie, Universität Bonn: Germany, 2010.

(27) Djukic, B.; Dube, P. A.; Razavi, F.; Seda, T.; Jenkins, H. A.; Britten, J. F.; Lemaire, M. T. Inorg. Chem. 2009, 48, 699.

(28) Kahn, O. Molecular Magnetism; VCH: Weinheim, Germany, 1993.

(29) Koch, S.; Holm, R. H.; Frankel, R. B. I. Am. Chem. Soc. 1975, 97, 6714

(30) Koch, S.; Tang, S. C.; Holm, R. H.; Frankel, R. B. J. Am. Chem. Soc. 1975, 97, 914.

(31) Weiss, R.; Gold, A.; Terner, J. Chem. Rev. 2006, 106, 2550.

(32) Maltempo, M. M.; Moss, T. H. Q. Rev. Biophvs. 1976, 9, 181.

(33) (a) Ohgo, Y; Chiba, Y.; Hashizume, D.; Uekusa, H.; Ozeki, T.; Nakamura, M. Chem. Commun. 2006, 1935. (b) Solomon, E. I.; Brunold, T. C.; Davis, M. I.; Kemsley, J. N.; Lee, S.-K.; Lehnert, N.; Neese, F.; Skulan, A. J.; Yang, Y.-S.; Zhou. J. Chem. Rev. 2000, 235.

(34) (a) Adhikari, D.; Mossin, S.; Basuli, F.; Huffman, J. C.; Szilagyi, R. K.; Meyer, K.; Mindiola, D. J. I. Am. Chem. Soc. 2008, 130, 3676.

(b) Harkins, S. B.; Mankad, N. P.; Miller, A. J. M.; Szilagyi, R. K.; Peters, J. C. I. Am. Chem. Soc. 2008, 130, 3478.

(35) (a) Keutel, H.; Käpplinger, I.; Jäger, E.-G.; Grodzicki, M.; Schünemann, V.; Trautwein, A. X. Inorg. Chem. 1999, 38, 2320. (b) Gismelseed, A.; Bominaar, E. L.; Bill, E.; Trautwein, A. X.; Winkler, H.; Nasri, H.; Doppelt, P.; Mandon, D.; Fischer, J.; Weiss, R. Inorg. Chem. 1990, 29, 2741.

(36) Beinert, H.; Holm, R. H.; Munck, E. Science 1997, 277, 653.

(37) Chun, H.; Weyhermüller, T.; Bill, E.; Wieghardt, K. Angew. Chem. Int. Ed. 2001, 40, 2489.

(38) Alonso, P. J.; Arauzo, A. B.; Forniés, J.; García-Monforte, M. A.; Martín, A.; Martínez, J. I.; Menjón, B.; Rillo, C.; Sáiz-Garitaonandia, J. I. Anoew. Chem. Int. Ed. 2006, 45, 6707.

(39) Merrithew, P. B.; Rasmussen, P. G. Inorg. Chem. 1972, 11, 325.

(40) Henderson, J. J.; Koo, C.; Feng, P. L.; del Barco, E.; Hill, S.; Tupitsyn, I. S.; Stamp, P. C. E.; Hendrickson, D. N. Phys. Rev. Lett. 2009, 103, 017202. 